\title{
Probable fungemia por Rhodotorula mucilaginosa asociada a catéter venoso central en un paciente pediátrico. Presentación de un caso
}

\author{
(Probable fungemia by Rhodotorula mucilaginosa associated to a central \\ venous catheter in a pediatric pacient. A case report)
}

\author{
Cerda Gianinna ${ }^{1}$, Haro César ${ }^{2}$. \\ ${ }^{1}$ Interna de Medicina, Universidad de Valparaíso. \\ ${ }^{2}$ Servicio de Pediatría, Hospital Carlos Van Buren, Valparaíso. \\ *Autor para correspondencia: : xxxxx@yyyyy \\ RECIBIDO:08 de Junio de 2017 \\ APROBADO:27 de Junio de 2017
}

DOI: 10.22370/bolmicol.2017.32.1.664

LOS AUTORES DECLARAN NO TENER CONFLICTO DE INTERESES

Palabras claves: Rhodotorula; catéter venoso central; inmunosuprimido.

Key words: Rhodotorula; central venous catéter; immunocompromised.

\section{RESUMEN}

Las levaduras del género Rhodotorula son patógenos oportunistas emergentes, especialmente en pacientes inmunocomprometidos. Se presenta el caso de un niño de 9 años con sarcoma de Ewing en tratamiento con quimioterapia que cursó con una probable fungemia por Rhodotorula mucilaginosa. Se identificaron varios factores de riesgo tales como la presencia de un catéter venoso central (CVC) y una neoplasia maligna sólida. El diagnóstico se realizó a través de un hemocultivo de una rama del CVC. Nuestra cepa fue identificada como R. Mucilaginosa por morfofisiología y pruebas bioquimicas. El éxito terapeutico se basó en el retiro del CVC y en el tratamiento con anfotericina $\mathrm{B}$ desoxicolato como primera alternativa.

\begin{abstract}
Yeasts from Rhodotorula genus are opportunistic pathogen that emerge especially in immunocompromised patients. We report a case of a 9-years-old boy, he developed an Ewing's sarcoma that was treated with chemotherapy an underwent with problable fungemia by Rhodotorula mucilaginosa. Several risk factors were identified such as presence of a central venous catheter (CVC) and a solid malignant neoplasm. The diagnosis was made by blood culture of a branch of the CVC. Our isolated was identified as R. mucilaginosa by morphofisiology and biochemical test. The therapy did success based on withdrawal of CVC and treatment with amphotericin B deoxycholate as the first alternative.
\end{abstract}




\section{INTRODUCCIÓN}

Las levaduras del género Rhodotorula pertenecientes a la división Basidiomycota, están emergiendo como una causa importante de infecciones nosocomiales y oportunistas ${ }^{1}$. Este género contiene 8 especies, sin embargo $R$. mucilaginosa y R.glutinis son las que se asocian con mayor frecuencia a infecciónes ${ }^{2}$. Son levaduras encapsuladas, rara vez forman pseudomicelios, crecen fácilmente en casi todos medios de cultivo, son ureasa positivo,inositol negativo y fermentan azúcar. Macroscópicamente, la mayoría de las especies de Rhodotorula producen colonias rojas anaranjadas debido a la presencia de pigmentos carotenoides ${ }^{3}$. Si bien es un contaminante habitual del laboratorio y puede ser aislada como colonizador de la piel y mucosas, se describen casos de infecciones en humanos.

Rhodotorula es un patógeno oportunista y su forma más común de presentación es la fungemia, aunque se han descrito también casos de endocarditis, peritonitis, meningitis, ventriculitis e infección diseminada. En la mayoría de los casos el cuadro clínico suele ser inespecífico y se asocia a la presencia de un catéter venoso central (CVC) en pacientes portadores de neoplasias malignas sólidas o hematológicas sometidos a quimioterapia citotóxica ${ }^{4}$ y/o tratamiento antibiótico o corticoesteroidal prolongado ${ }^{2,5}$.

El objetivo del presente reporte es presentar un probable caso de fungemia por $R$. mucilaginosa y revisar brevemente los factores de riesgo, formas de presentación, diagnóstico y tratamiento.

\section{Caso clínico}

Niño de 9 años de edad, portador de un sarcoma de Ewing peroneo izquierdo diagnosticado a los 5 años, que fue tratado con quimio y radioterapia. Atendido en el Servicio de Pediatría del Hospi- tal Carlos van Buren de Valparaíso y que en agosto de 2016 presentó una recaída en peroné derecho, por lo que se reinició la quimioterapia.

En febrero de 2017 durante el séptimo ciclo con topotecán y ciclofosfamida, presentó un pico febril de $38,6^{\circ} \mathrm{C}$ sin otros síntomas, asociado a leucopenia leve $(4.100 / \mu \mathrm{L})$ que posteriormente se acentuó (1.600/ $\mu \mathrm{L}$ con $89 \%$ polimorfonucleares) y proteína $\mathrm{C}$ reactiva (PCR) de $90 \mathrm{mg} / \mathrm{l}$ (que alcanza $147 \mathrm{mg} / 1$ en los días siguientes). Los hemocultivos periféricos y el urocultivo resultaron negativos $\mathrm{y}$ en el hemocultivo tomado desde una rama del CVC creció una levadura a las 43 hrs, iniciciandose tratamiento con anfotericina B desoxicolato.

A los dos días se retiró el CVC y al $7^{\circ}$ día se informó la identificación de $R$. mucilaginosa. Exámenes de control: recuento de leucocitos 1700/ $\mu \mathrm{L}$, RAN 578/mm3, Hto 28\%, Plaquetas 200.000/ $\mu \mathrm{L}$, PCR $24 \mathrm{mg} / \mathrm{l}$, función renal normal.

El paciente recibió tratamiento antifúngico durante 14 días con buena respuesta, siendo dado de alta luego de completado su ciclo de quimioterapia.

\section{Identificación de la especie}

Características de la colonia: en agar con extracto de malta o en otros medios adquiere un color rojo coral a rosa, brillantes, lisas o ásperas, suaves, mucosas (imágenes 1 y 2).

Microscopía óptica: se observan células elipsoidales, de 2.5-6.5 x 2.0-5.5 $\mu \mathrm{m}$, unipolares; un pseudomicelio rudimentario puede estar presente.

\section{DISCUSIÓN}

Estudios recientes en Estados Unidos ${ }^{6}$ y Europa $^{7}$ describen una incidencia de fungemia causada por Rhodotorula entre 0.5 y $2.3 \%$ en po- 


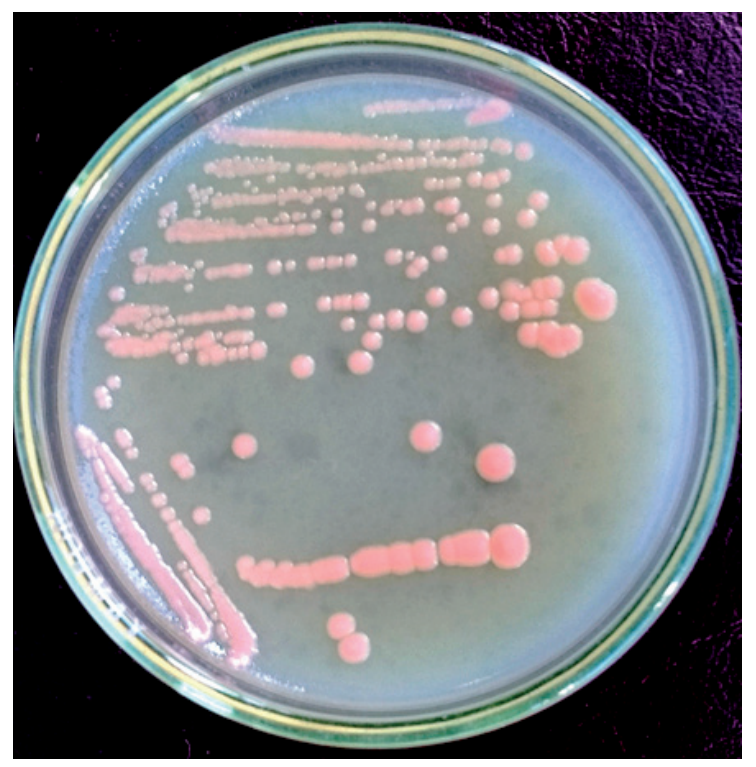

Figura 1. Se observan colonias de color rosado brillante de rapido crecimiento en agar Sabouraud.

blación de riesgo. No existen estudios de prevalencia en Chile.

Rhodotorula es una levadura pigmentada perteneciente a la división Basidiomycota. Aunque previamente se consideró no patogénica, durante las últimas décadas ha surgido como agente etiológico oportunista, especialmente en casos de fungemia asociada a $\mathrm{CVC}^{8}$.

Según una revisión sistemática de 128 casos publicados, el $87 \%$ de las infecciones por Rhodotorula se asoció con inmunosupresión o cáncer, y el factor de riesgo aislado independiente más común es el uso de un CVC. Los casos publicados que involucran a niños son predominantemente aquellos con neoplasias hematológicas o tumores sólidos ${ }^{9}$. En el caso reportado, los principales factores de riesgo fueron la presencia de un CVC y una neoplasia maligna sólida en tratamiento con quimioterapia citotóxica.

En este caso el diagnóstico se realizó a través del hemocultivo de una rama del CVC, a pe-

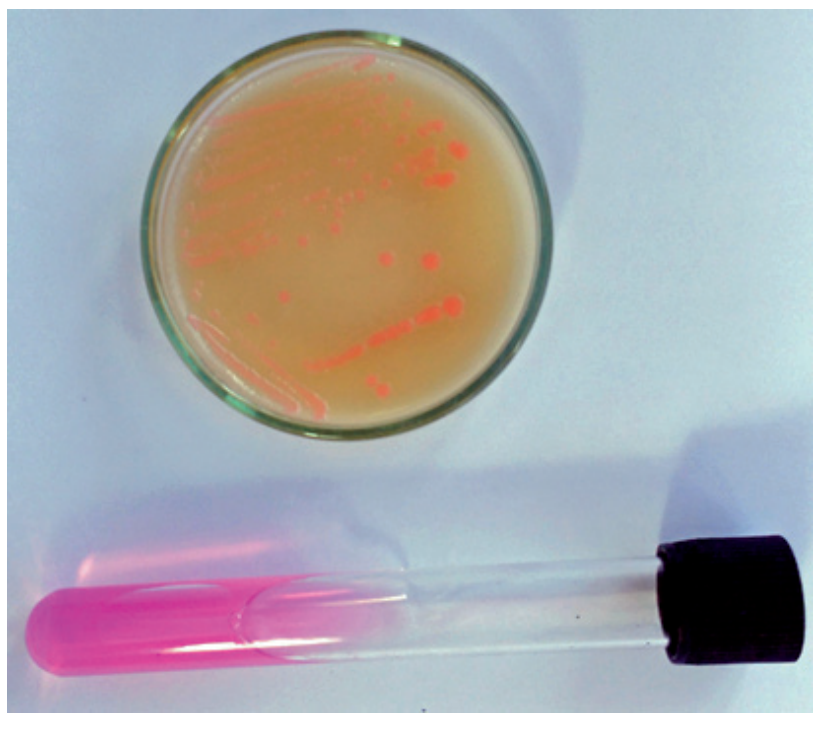

Figura 2. Se observa colonia de color rosado brillante en agar Sabouraud. Tambien se observa reacción positiva en medio de agar urea (tubo).

sar de que los hemocultivos periféricos resultaron negativos, por lo que no se puede descartar una colonización del CVC. Eso sí, cabe destacar que en una revisión sistemática realizada por Tuon et $a 1^{10}$, en un significativo número de casos los hemocultivos estaban negativos o no se obtuvo dicha información, por lo que el diagnóstico se basó en el hemocultivo obtenido del CVC.

La cepa fue identificada como R. mucilaginosa, que es la especie que con mayor frecuencia causa fungemias (75\%), seguida de $R$. glutinis $(7 \%)^{9}$.

Se han llevado a cabo varios estudios in vitro para predecir la respuesta in vivo de Rhodotorula frente a agentes antifúngicos. En un estudio se realizaron pruebas de susceptibilidad de veintinueve cepas de Rhodotorula en donde sólo una fue resistente a anfotericina $\mathrm{B}$, y la susceptibilidad a azoles como itraconazol y voriconazol fue limita$\mathrm{da}^{11}$. Otro estudio en el que se analizaron 210 cepas de Rhodotorula, la resistencia al fluconazol y voriconazol fue de 49 y $37 \%$ respectivamente ${ }^{12}$. 
El éxito del tratamiento se basa en 2 pilares: el retiro del CVC cuando es el origen de la infección y el tratamiento con anfotericina B como primera alternativa ${ }^{13}$.
El paciente fue tratado con anfotericina $B$ desoxicolato con buena respuesta clínica, siendo dado de alta sin complicaciones.

\section{REFERENCIAS}

1. Guidara R, Trabelsi H, Neji S, Cheikhrouhou F, Sellami H, Makni F, et al. Rhodotorula fungemia: Report of two cases in Sfax (Tunisia). J Mycol Med. 2016; 26 (2); 178-81.

2. Vazquez JA. Rhodotorula, Saccharomyces, Malassezia, Trichosporon, Blastoschizomyces, and Sporobolomyces. In Kauffman CA, Pappas PG, Sobel JD, Dismukes WE, editors. Essential of clinical mycology. New York: Springer; 2011: 227-239.

3. Reyes I, Pérez L, Morffi M, Barletta J. Aislamiento de Rhodotorula. Presentación de un caso en paciente con leucemia mieloide aguda. Medisur [Internet]. 2013 [citado 27 Feb 2017]; 11(5): 542545. Disponible en: http://medisur.sld.cu/index. $\mathrm{php} /$ medisur/article/view/2542

4. Wirth F, Goldani LZ. Epidemiology of Rhodotorula: An Emerging Pathogen. Interdiscip Perspect Infect Dis. 2012; 2012: 1-7.

5. Verdugo F, Briones E, Porte L, Amaro J, Fica A. Peritonitis fúngica por Rhodotorula mucilaginosa en una paciente en diálisis peritoneal automatizada. Revisión de la literatura. Rev Chilena Infectol. 2016; 33 (2): 222-225.

6. Lunardi LW, Aquino VR, Zimerman RA, Goldani LZ. Epidemiology and outcome of Rhodotorula fungemia in a tertiary care hospital. Clin Infect Dis 2006; 43 (6): e60-e63.

7. Duboc de Almeida GM, Costa SF, Melhem M.
Rhodotorula spp. isolated from blood cultures: clinical and microbiological aspects. Med Mycol, vol. 46 (6): 547-556, 2008.

8. Duggal S. Rhodotorula fungemia: two cases and a brief review.Med MycolNovember 2011, 49, 879-882.

9. Tuon FF, Costa SF. Rhodotorula infection. a systematic review of 128 cases from literatura. Rev Iberoam Micol 2008; 25: 135-140.

10. Tuon FF. Central venous catheter-associated fungemia due to Rhodotorula spp. A systematic review. Med Mycol August 2007, 45, 441-447.

11. Gomez-Lopez A, Mellado E, Rodriguez-Tuleda JL,Cuenca-Estrella M. Susceptibility profile of 29 isolates of Rhodotorula spp. and literature review. J Antimicrob Chemother. 2005;55:312-6.

12. Pfaller MA, Diekema DJ. Global antifungal surveillancestudy. Results from the ARTEMIS DISK global surveillancestudy, 1997 to 2005: an 8.5-year analysis of susceptibilities of Candida species and other yeast species to Fluconazole and Voriconazole determined by CLSI standardized disk diffusion testing. J Clin Microbiol. 2007;45:1735-45.

13. Ramos A, Cabero M, Orden B, Ángel-Moreno A, Forés R. Fungemia por Rhodotorula mucilaginosa. Presentación de dos casos. RevEspQuimioter 2012; 25(1):76-78. 